\title{
Erratum to: Post-transcriptional silencing of Notch2 mRNA in chronic lymphocytic leukemic cells of B-CLL patients
}

\author{
Kaneez Fatima • Rehan Zafar Paracha • \\ Ishtiaq Qadri
}

Published online: 31 March 2012

(C) Springer Science+Business Media B.V. 2012

Erratum to: Mol Biol Rep (2012) 39:5059-5067

DOI 10.1007/s11033-011-1301-5

There is a major typographical error in the Title: the term 'lymhocytic' should be spelled 'lymphocytic'.

An issue was raised by a third party about the provenance of these data, and the attached new Fig. 3 will address this issue.

The online version of the original article can be found under doi:10.1007/s11033-011-1301-5.

\section{K. Fatima $\cdot$ R. Z. Paracha}

NUST Centre of Virology and Immunology (NCVI), National University of Sciences and Technology (NUST), Sector H-12, Islamabad, Pakistan

\section{Qadri ( $\square)$}

Biotech Park Faculty of Biological Sciences, Quaid-e-Azam

University, 3rd Avenue, Islamabad, Pakistan

e-mail: ishtiaq80262@yahoo.com

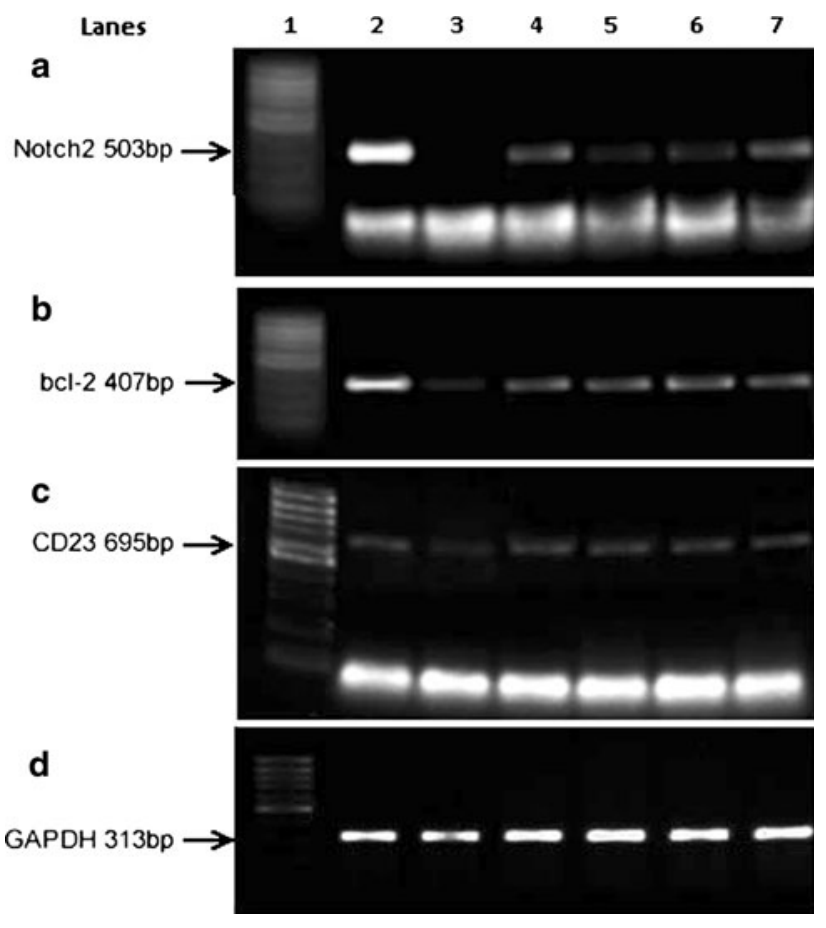

Fig. 3 Notch2 down-regulation by AS1 causes a decrease in bcl-2 and CD23 Expression. Lane 1 shows 100 bp ladder and lane 2 shows control without AS-ODN. a-c with lanes 3-6 show respective effect of AS1, AS2, AS3 and AS4 on mRNAs of Notch2, bcl-2 and CD23, respectively. Lane 7 shows effect of non-specific ODN (ASN) on the expression of Notch2, bcl2 and CD23

Acknowledgments The authors thank Dr. Ishrat Waheed for initial supervision of the work and Dr. Riazzudin Ex Director CEMB, Lahore for the financial support to carry out the research work. 